\title{
Prevalence and Characteristics of Coronary-Cameral Communications in Adult Patients: Coronary Angiographic Analysis of 16,573 Patients
}

\author{
Serkan Yuksel Erdogan Yasar Gokay Nar Okan Gulel Sabri Demircan \\ Ozcan Yilmaz Mahmut Sahin
}

Department of Cardiology, Faculty of Medicine, Ondokuz Mayıs University, Samsun, Turkey

\author{
Key Words \\ Congenital coronary anomaly · Coronary-cameral \\ communication · Fistula
}

\begin{abstract}
Objective: To analyze the coronary angiograms of patients with symptomatic heart disease in order to determine the frequency and characteristics of coronary-cameral communications (CCCs) in a single center. Subjects and Methods: The coronary angiograms of 16,573 patients with symptomatic heart disease performed from November 2001 to January 2011 were analyzed. The diagnosis of coronary fistula and coronary-cameral microcommunications (CCMCs) was made according to previously defined criteria. Results: Of the 16,573 patients, 15 (0.09\%; 8 males and 7 females, mean age $63 \pm 12$ years) had CCCs, while coronary fistulas were identified in $2(0.01 \%)$. In the first patient, the coronary fistula arose from the branches of the left anterior descending (LAD) artery and the right coronary artery (RCA) and drained into the right ventricle. In the second patient, the fistula originated from branches of the LAD artery, the circumflex (Cx) artery and the RCA and drained into the left ventricle. In 7 patients, the CCMCs originated from the LAD artery. In 3 pa-
\end{abstract}

tients, the Cx artery was the origin. The CCMCs originated from the RCA in 2 patients. In 1 patient the CCMC took its origin from the RCA and the Cx artery, while in 2 patients the CCMCs were associated with intracardiac masses in the left atrium and the right atrium, respectively. Conclusion: The prevalence of CCCs in adult patients was low and that of large coronary fistulas was even lower; coronary fistulas are probably very rare in adult patients because the majority of them are detected and treated during childhood.

() 2014 S. Karger AG, Basel

\section{Introduction}

Coronary-cameral communications (CCCs) are the anomalies of coronary artery termination and include coronary fistulas and coronary-cameral microcommunications (CCMCs). The CCCs are described as unusual congenital or acquired coronary artery abnormalities in which blood is shunted into a cardiac chamber, great vessel or other structures such as coronary sinus and pulmonary veins, bypassing the myocardial capillary network [1]. They are the most common congenital coronary anomalies affecting hemodynamic parameters.

\begin{tabular}{ll}
\hline KARGER & $\begin{array}{l}\text { @ 2014 S. Karger AG, Basel } \\
1011-7571 / 14 / 0234-0336 \$ 39.50 / 0 \quad \text { Karger }\end{array}$ \\
E-Mail karger@karger.com & $\begin{array}{l}\text { This is an Open Access article licensed under the terms of the } \\
\text { Creative Commons Attribution-NonCommercial 3.0 Un- } \\
\text { ported license (CC BY-NC) (www.karger.com/OA-license), } \\
\text { applicable to the online version of the article only. Distribu- } \\
\text { tion permitted for non-commercial purposes only. }\end{array}$
\end{tabular}

Serkan Yüksel

Department of Cardiology, Faculty of Medicine

Ondokuz Mayss University

TR-55139 Samsun (Turkey)

E-Mail serkan.yuksel@omu.edu.tr 
Many of the CCCs are small and detected incidentally during coronary angiography in adult patients. Angiographic series reveal a prevalence of $0.09-0.5 \%$ [2-6]. Large coronary fistulas are usually symptomatic and cause symptoms of ischemia mostly due to coronary steal. Their clinical importance in adulthood is due to an increased risk of complications, including heart failure, myocardial ischemia, infective endocarditis, arrhythmias, and rupture. Coronary fistulas might even cause sudden cardiac death. Small CCCs are usually benign and do not cause clinical symptoms [1,7-10].

In this study, coronary angiograms performed over a 10 -year period were analyzed to determine the prevalence and characteristics of CCCs in a single center.

\section{Subjects and Methods}

All patients who underwent coronary angiography in the cardiac catheterization laboratories from November 2001 to January 2011 were included in this study. The coronary angiograms of 16,573 patients with symptomatic heart disease were analyzed and those with CCCs were selected for further assessment. All the coronary angiographies were performed for the suspicion of ischemic heart disease. Two independent experienced observers (S.Y. and O.G.) reviewed all the coronary angiograms and reached a consensus on the origin and termination of the CCCs.

A diagnosis of coronary fistula was made if there was at least one of the following features: definite signs of fistulous flow (for instance, the affected feeding vessel had a luminal diameter of at least $50 \%$ of the expected diameter) or angiographically clear and prompt visualization of the receiving cardiovascular structure where a step-up in the concentration of oxygen was apparent. The rest of the connections were defined as CCMCs.

\section{Results}

Of the 16,573 patients, $11,273(68 \%)$ were males and $5,300(32 \%)$ were females with a mean age $60 \pm 13$ years, who underwent coronary angiography. CCCs were found in 15 patients $(0.09 \%$; mean age $63 \pm 12$ years): 8 (53\%) were males and 7 (47\%) were females. Coronary fistulas were identified in $2(0.01 \%)$ patients.

The origins of CCCs are shown in table 1 . In 1 patient, the coronary fistula originated from branches of the left anterior descending (LAD) artery (fig. 1a) and the right coronary artery (RCA) (fig. 1b), while in another patient the fistula originated from branches of the LAD artery, the circumflex (Cx) artery (fig. 1c), and the RCA (fig. 1d). However, the CCMCs originated from the LAD artery in $7(46.6 \%)$ patients, from the Cx artery in $3(20 \%)$ patients,
Table 1. The prevalence of CCCs according to the artery of origin $(\mathrm{n}=15)$

\begin{tabular}{|c|c|c|c|}
\hline Origin & $\begin{array}{l}\text { Patients, } \\
\mathrm{n}\end{array}$ & $\begin{array}{l}\text { Angiographic } \\
\text { prevalence, } \\
\%\end{array}$ & $\begin{array}{l}\text { Anomaly } \\
\text { prevalence, } \\
\%\end{array}$ \\
\hline LAD artery & 7 & 0.42 & 46.6 \\
\hline Cx artery & 3 & 0.018 & 20 \\
\hline $\mathrm{RCA}$ & 2 & 0.012 & 13.3 \\
\hline RCA and Cx artery & 1 & 0.006 & 6.7 \\
\hline LAD artery and RCA & 1 & 0.006 & 6.7 \\
\hline LAD artery, $\mathrm{Cx}$ artery, and RCA & 1 & 0.006 & 6.7 \\
\hline
\end{tabular}

Table 2. The prevalence of CCMs according to sites of drainage $(\mathrm{n}=15)$

\begin{tabular}{llll}
\hline Site of drainage & $\begin{array}{l}\text { Patients, } \\
\mathrm{n}\end{array}$ & $\begin{array}{l}\text { Angiographic } \\
\text { prevalence, } \\
\%\end{array}$ & $\begin{array}{l}\text { Anomaly } \\
\text { prevalence, } \\
\%\end{array}$ \\
\hline Right ventricle & 4 & 0.024 & 27 \\
Left ventricle & 4 & 0.024 & 27 \\
Left atrium & 4 & 0.024 & 27 \\
Right atrium & 2 & 0.012 & 12 \\
Pulmonary trunk & 1 & 0.006 & 7 \\
\hline
\end{tabular}

from the RCA in $2(13.3 \%)$ patients, and from the RCA and $\mathrm{Cx}$ artery in $1(6.6 \%)$ patient.

The drainage sites of the CCCs are shown in table 2 . The CCCs drained into the left side of the heart in 8 (54\%) patients and into the right side of the heart in 7 (46\%) patients. In the left side of the heart, 4 (27\%) CCCs drained into the left atrium and the other $4(27 \%)$ drained into the left ventricle. The CCCs in the right side of the heart drained into the right ventricle in $4(27 \%)$ patients, into the right atrium in $2(12 \%)$ patients, and into the pulmonary trunk in $1(7 \%)$ patient.

The symptoms of patients with CCCs on clinical presentation were chest pain in $8(53 \%)$, shortness of breath in $6(40 \%)$, and syncope in $1(7 \%)$. Five patients presented at the emergency department with acute coronary syndromes. Congestive heart failure and left ventricular dysfunction were diagnosed in 4 patients. In 2 patients with dyspnea, huge left atrial thrombus and right atrial myxoma were detected on transthoracic echocardiographic examinations. Ventricular tachycardia was diagnosed in 1 patient. The treatment modalities were percutaneous coronary intervention in 5 patients, surgical excision of in- 
Fig. 1. The coronary fistula arose from branches of the LAD artery $(\mathbf{a}, \mathbf{b})$ and the RCA (c) and drained into the right ventricle. The fistula originated from branches of the LAD artery (d), the Cx artery (e), and the RCA (f) and drained into the left ventricle.

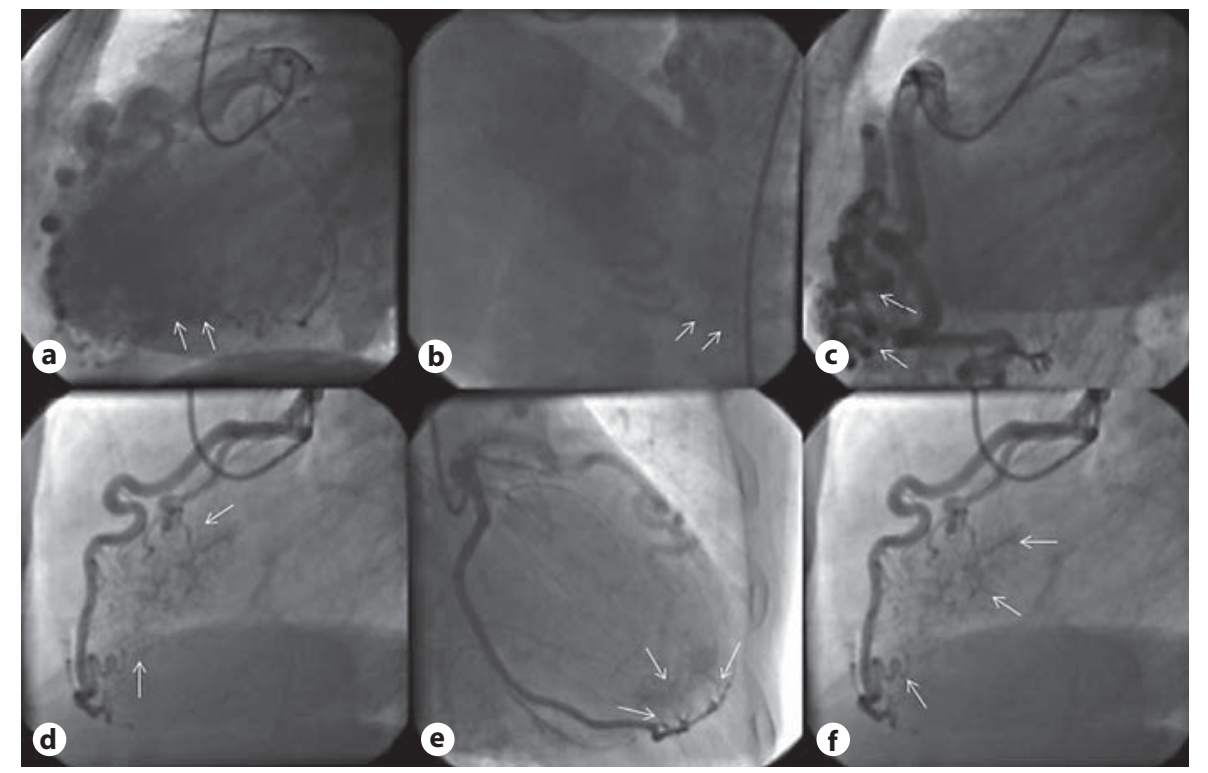

tracardiac masses and associated CCCs in 2 patients, and percutaneous transluminal coil embolization of fistulas followed by implantable cardioverter defibrillator implantation in 1 patient. The remaining 7 patients were followed by conservative medical treatment. Only 1 (7\%) patient with acute anterior myocardial infarction died during in-hospital follow-up because of the cardiogenic shock due to severe left ventricular dysfunction.

\section{Discussion}

The finding of $9.09 \%$ prevalence of CCC in this study is within the range of $0.09-0.5 \%$ which has been previously reported [2-6]. Unlike in a study with a female preponderance [6], no gender difference was seen in this study. The mean age of $63 \pm 12$ years in this study is similar to that in other reports in which the mean ages were between 59 and 61 years $[5,6]$.

The left anterior descending artery was the most common originating artery of CCCs in our cases, which confirmed the report by Chiu et al. [5]. Equally, the RCA as a major source of CCCs has been reported previously [11]. Our finding of $20 \%$ for the Cx artery as the origin of CCCs is slightly higher than the $18 \%$ reported previously [12]. The variation could be due to geographical and ethnic differences of the populations analyzed in these studies.

Although a fistulous communication to the left-sided chambers was reported to be less frequent, we found that more than half (54\%) of CCCs drained into the left heart. However, Said et al. [6] found the left side of the heart to be the major drainage or termination site in their case series but over $90 \%$ of the fistulas from either coronary artery drained to the right side of the heart and the remaining $10 \%$ drained to the left side of the heart $[5,13]$. This difference might be caused by the relatively small number of patients from different geographical origins. In the right heart, drainage occurs most frequently to the right ventricle, followed by the right atrium, coronary sinus, and pulmonary trunk [13]. However, Chiu et al. [5] reported that the pulmonary trunk was the most common drainage site. We only found $27 \%$ of CCCs draining to the right ventricle, $12 \%$ to the right atrium, and $7 \%$ to the pulmonary trunk. Therefore, as mentioned in the context of the origin of CCCs, geographical and ethnic differences could affect the termination of CCCs as well.

While coronary artery fistulas in the majority of adult patients are usually asymptomatic [7, 14], $0.01 \%$ of the patients in our study were symptomatic. Generally, coronary fistulas with large intracardiac shunts are very rare in adult patients because the majority of these shunts are detected and repaired during childhood.

The treatment options for coronary arterial fistulas include surgery or catheter closure. The indications for treatment of coronary arterial fistulas include the presence of a large or increasing left-to-right shunt, left ventricular volume overload, myocardial ischemia, left ven- 
tricular dysfunction, congestive cardiac failure, and prevention of endocarditis/endarteritis $[1,15]$.

The main limitation of this study was that the coronary angiographies were only performed in symptomatic patients with suspected coronary artery disease. Therefore, these results may not reflect the exact prevalence of CCCs in the population.

\section{Conclusion}

The prevalence of CCCs in adult patients was low and that of large coronary fistulas was even lower; coronary fistulas are probably very rare in adult patients because the majority of them are detected and treated during childhood.

\section{References}

1 Angelini P, Villason S, Chan AV, et al: Nor$\mathrm{mal}$ and anomalous coronary arteries in humans; in Angelini P (ed): Coronary Artery Anomalies: A Comprehensive Approach. Philadelphia, Lippincott Williams \& Wilkins, 1999, pp 60-63.

$\checkmark 2$ Yamanaka O, Hobbs RE: Coronary artery anomalies in 126,595 patients undergoing coronary arteriography. Catheter Cardiovasc Diagn 1990;21:28-40.

3 Vavuranakis M, Bush CA, Boudoulas H: Coronary artery fistulas in adults: incidence, angiographic characteristics, natural history. Cathet Cardiovasc Diagn 1995;35:116-120.

4 Said SA, van der Werf T: Dutch survey of coronary artery fistulas in adults: congenital solitary fistulas. Int J Cardiol 2006;106:323-332.
Chiu CZ, Shyu KG, Cheng JJ, et al: Angiographic and clinical manifestations of coronary fistulas in Chinese people: 15-year experience. Circ J 2008;72:1242-1248.

6 Said SA, Schiphorst RH, Derksen R, et al: Coronary-cameral fistulas in adults (first of two parts). World J Cardiol 2013;5:329-336.

7 Balanescu S, Sangiorgi G, Castelvecchio S, et al: Coronary artery fistulas: clinical consequences and methods of closure: a literature review. Ital Heart J 2001;2:669-676.

8 Wang NK, Hsieh LY, Shen CT, et al: Coronary arteriovenous fistula in pediatric patients: a 17-year institutional experience. J Formos Med Assoc 2002;101:177-182.

$>9$ Levin DC, Fellows KE, Abrams HL: Hemodynamically significant primary anomalies of the coronary arteries. Circulation 1978;58:25-34.

-10 Ceyhan K, Koc F, Ozdemir K, et al: Coronary ectasia is associated with impaired left ventricular myocardial performance in patients without significant coronary artery stenosis. Med Princ Pract 2012;21:139-144.
11 Black IW, Loo CK, Allan RM: Multiple coronary artery-left ventricular fistulae: clinical, angiographic, and pathologic findings. Cathet Cardiovasc Diagn 1991;23:133-135.

12 McNamara JJ, Gross RE: Congenital coronary artery fistula. Surgery 1969;65:59-69.

13 Stierle U, Giannitsis E, Sheikhzadeh A, et al: Myocardial ischemia in generalized coronary artery-left ventricular microfistulae. Int J Cardiol 1998;63:47-52.

14 Gowda RM, Vasavada BC, Khan IA: Coronary artery fistulas: clinical and therapeutic considerations. Int J Cardiol 2006;107:7-10.

15 Qureshi SA: Coronary arterial fistulas. Orphanet J Rare Dis 2006;1:51. 